\title{
Developing a decomposable measure of profit efficiency using DEA
}

\author{
MCAS Portela ${ }^{1,2}$ and E Thanassoulis ${ }^{2 *}$ \\ ${ }^{1}$ Centro Regional do Porto, Universidade Católica Portuguesa, Porto, Portugal; and \\ ${ }^{2}$ Aston Business School, Aston Triangle, Birmingham, UK
}

\begin{abstract}
In for-profit organizations efficiency measurement with reference to the potential for profit augmentation is particularly important as is its decomposition into technical, and allocative components. Different profit efficiency approaches can be found in the literature to measure and decompose overall profit efficiency. In this paper, we highlight some problems within existing approaches and propose a new measure of profit efficiency based on a geometric mean of input/output adjustments needed for maximizing profits. Overall profit efficiency is calculated through this efficiency measure and is decomposed into its technical and allocative components. Technical efficiency is calculated based on a non-oriented geometric distance function (GDF) that is able to incorporate all the sources of inefficiency, while allocative efficiency is retrieved residually. We also define a measure of profitability efficiency which complements profit efficiency in that it makes it possible to retrieve the scale efficiency of a unit as a component of its profitability efficiency. In addition, the measure of profitability efficiency allows for a dual profitability interpretation of the GDF measure of technical efficiency. The concepts introduced in the paper are illustrated using a numerical example.
\end{abstract}

Keywords: profit efficiency; data envelopment analysis; decomposition

\section{Introduction}

The data envelopment analysis (DEA) (Charnes et al, 1978) literature has tended to focus on technical efficiency, which can be computed without reference to input or output prices. However, in for-profit organizations technical efficiency alone is of limited interest, as firms will normally be reluctant to change input and output quantities if these do not lead to monetary gains. Obviously, the translation of input and output changes into profit requires price information.

In order to measure profit efficiency and lead operating units to improved profitability, a non-oriented approach is needed which will allow both for increases and decreases in inputs and in outputs so as to exploit prevailing prices. Typically in for-profit situations a mix of inputs and outputs is endogenous and management can seek to change their values (eg Kumbhakar, 2001). Moreover, it is useful to know the component of the scope of profit improvement that can be achieved through improving technical efficiency and the component that can be achieved through adjusting the inputoutput mix to take advantage of prevailing input-output prices. Such information can be obtained through decomposing the measure of overall profit efficiency into technical efficiency (reflecting how much a production unit can increase outputs and decrease inputs) and allocative efficiency

*Correspondence: MCAS Portela, Universidade Católica Portuguesa, Centro Regional do Porto, R. Diogo Botelho, 1327 Porto, Portugal. E-mail: csilva@porto.ucp.pt or portemca@aston.ac.uk (reflecting additional profit attainable beyond that through a unit becoming technically efficient, the additional profit being attainable through changes in the input-output mix).

In this paper, we address two related issues: Measurement of technical efficiency through non-oriented measures, and measurement of profit efficiency and its decomposition. To measure technical efficiency in a profit setting we use the geometric distance function (GDF) introduced by Portela and Thanassoulis (2005) and explore its properties. The GDF is also used to measure and decompose overall profit efficiency. An alternative measure to profit efficiency is also presented that is intended to capture profitability rather than profit as defined in accounting terms. This measure of profitability allows a dual profitability interpretation of the GDF measure of technical efficiency.

In the next section, we detail the GDF measure of technical efficiency and its properties. In the succeeding section, existing approaches for calculating and decomposing profit efficiency are outlined. In the section, that follows we present a new measure of profit efficiency based on the GDF and illustrate its calculation and decomposition through an example. Finally in the last section, the concept of profitability efficiency is defined and its decompositions and use are discussed.

\section{A geometric distance function (GDF)}

Consider a technology represented by $T=\left\{(x, y) \in R^{m+s}+\mathbf{x}\right.$ can produce $\mathbf{y}\}$, where $\mathbf{x}$ is an input vector $(i=1, \ldots, m)$, and 
$\mathbf{y}$ is an output vector $(r=1, \ldots, s)$. We will assume throughout that $T$ is represented by the following production possibility set:

$$
\begin{gathered}
T=\left\{(\mathbf{x}, \mathbf{y}) \in R_{+}^{m+s} \mid \sum_{j=1}^{n} \lambda_{j} \mathbf{y}_{\mathbf{j}} \geqslant \mathbf{y}, \quad \sum_{j=1}^{n} \lambda_{j} \mathbf{x}_{\mathbf{j}} \leqslant \mathbf{x},\right. \\
\left.\sum_{j=1}^{n} \lambda_{j}=1, \lambda_{j} \geqslant 0, j=1, \ldots n\right\}
\end{gathered}
$$

That is, $\mathrm{T}$ is a monotonic (or strongly free disposable) convex set satisfying variable returns to scale (VRS) (for details see eg Färe et al, 1994).

To summarize the GDF measure first introduced in Portela and Thanassoulis (2005) let us, in a two-dimensional space, define an observed point $(x, y)$ and a target point $\left(x^{*}, y^{*}\right)$ on the frontier of $T$. The radial output technical efficiency measure is $y / y^{*}$, while the radial input technical efficiency measure is $x / x^{*}$. Both measures are in fact equal to a ratio between the productivity (ratio of output to input) at the observed and at the target point $(y / x) /\left(y^{*} / x^{*}\right)$. The output efficiency measure is derived if we set in the foregoing ratio $\left(x^{*}=x\right)$ and the input efficiency if we set $\left(y^{*}=y\right)$. Note now that $(y / x) /\left(y^{*} / x^{*}\right)$ can also be expressed as a ratio of target to observed input and output levels: $\left(x^{*} / x\right) /\left(y^{*} / y\right)$. We generalize this latter ratio to a multi-input multi-output context as follows.

Consider in the multiple input/output space an observed vector $(\mathbf{x}, \mathbf{y})$ and a target vector $\left(\mathbf{x}^{*}, \mathbf{y}^{*}\right)$ on the frontier of $T$. The traditional radial approach for measuring technical efficiency takes the maximum of $\mathbf{x}^{*} / \mathbf{x}=x_{1}^{*} / x_{1}, x_{2}^{*} / x_{2}, \ldots$, $x_{\mathrm{m}}^{*} / x_{\mathrm{m}}$ (which equals $\max \left(\mathbf{x}^{*} / \mathbf{x}\right) /\left(\mathbf{y}^{*} / \mathbf{y}\right)$ when $\left.\mathbf{y}^{*}=\mathbf{y}\right)$ as the input radial efficiency measure. Similarly, the maximum of $\mathbf{y} / \mathbf{y}^{*}$ or the minimum of $\mathbf{y}^{*} / \mathbf{y}$ (which equals $\max \left(\mathbf{x}^{*} / \mathbf{x}\right) /$ $\left(\mathbf{y}^{*} / \mathbf{y}\right)$ when $\left.\mathbf{x}^{*}=\mathbf{x}\right)$ is the output radial efficiency measure.

This means that the analogous situation in the nonoriented case would be to take the maximum of $\left(\mathbf{x}^{*} / \mathbf{x}\right) /\left(\mathbf{y}^{*} / \mathbf{y}\right)$ as the efficiency measure, where no inputs or outputs are considered fixed. If we now assume that between $(\mathbf{x}, \mathbf{y})$ and $\left(\mathbf{x}^{*}, \mathbf{y}^{*}\right)$ all inputs change by the same proportion ( say $\mathbf{x}^{*}=\theta \mathbf{x}$ ), and all outputs change by the same proportion $\left(\right.$ say $\left.\mathbf{y}^{*}=\beta \mathbf{y}\right)$, then $\left(\mathbf{x}^{*} / \mathbf{x}\right) /\left(\mathbf{y}^{*} / \mathbf{y}\right)=(\theta \mathbf{x} / \mathbf{x}) /(\beta \mathbf{y} / \mathbf{y})=\theta / \beta$ corresponds to the non-oriented efficiency measure, defined as a ratio of target to observed input level divided by the ratio of target to observed output level. If finally we consider the more general case, where inputs and outputs are allowed to change by different proportions (so that $x_{i}^{*}=\theta_{i} x_{i}$ and $y_{r}^{*}=\beta_{r} y_{r}$ ), then the measure in (2) parallels the foregoing ratio of target to observed input-output levels.

$$
\text { Geometric distance function }(\mathrm{GDF})=\frac{\left(\prod_{i} \theta_{i}\right)^{1 / m}}{\left(\prod_{r} \beta_{r}\right)^{1 / s}}
$$

The geometric distance function defined in (2) incorporates as special cases the usual input- and output-oriented measures of technical efficiency in DEA. Consider a GDF technical efficiency measure of $\left(\mathbf{x}_{\mathrm{o}}, \mathbf{y}_{\mathrm{o}}\right)$ as the solution of model (3).

$$
\begin{aligned}
G D F\left(\mathbf{x}_{\mathrm{o}}, \mathbf{y}_{\mathrm{o}}\right)= & \min \left\{\frac{\left(\prod_{i} \theta_{i o}\right)^{1 / m}}{\left(\prod_{r} \beta_{r o}\right)^{1 / s}} \mid \sum_{j=1}^{n} \lambda_{j} y_{r j}=\beta_{r o} y_{r o},\right. \\
& \sum_{j=1}^{n} \lambda_{j} x_{i j}=\theta_{i o} x_{i o}, \sum_{j=1}^{n} \lambda_{j}=1, \lambda_{j} \geqslant 0, \\
& \left.0 \leqslant \theta_{i o} \leqslant 1, \quad \beta_{r o} \geqslant 1\right\}
\end{aligned}
$$

Model (3) is highly nonlinear, but it becomes linear for the special cases corresponding to traditional oriented DEA models. For example, in input-oriented DEA models one assumes that $\beta_{r o}=\beta=1 \forall r$, and also that $\theta_{i o}=\theta \forall i$, and thus the final efficiency score in (3) reduces to $\theta$, which corresponds to the Farrell input efficiency measure. For output-oriented efficiency measures similar reasoning applies. If $\beta_{r o}=\beta \forall r, \theta_{i o}=\theta \forall i$ and $\beta=1 / \theta$, then (3) reduces to the hyperbolic model of Färe et al (1985), with the only difference being that the resulting measure of efficiency is $\theta^{2}$ and not $\theta$.

The advantage of allowing for different contraction factors associated with inputs $\left(\theta_{i}\right)$ and different expansion factors associated with outputs $\left(\beta_{r}\right)$ is that all sources of technical inefficiency can be captured by the resulting efficiency measure. This is not a new concern. For example, Färe et al (1985) introduced an additive 'Russell graph measure of technical efficiency' that allows for different changes within inputs and outputs. However, the authors define the arithmetic average of the various factors associated with inputs and outputs, $\left(\sum_{i=1}^{m} \theta_{i o}+\sum_{r=1}^{s} 1 / \beta_{r o}\right) / m+s$, as the final efficiency measure (see also Pastor et al, 1999, who propose an 'enhanced Russell graph efficiency' measure). However, as has been shown above, in order to retain the meaning of traditional efficiency measurement the geometric average between these factors should be used instead. In fact Färe et al (2002), also introduced a Multiplicative Russell Measure that is equivalent to the input-oriented GDF measure, where $\beta_{r o}=1, \forall r$.

\section{Properties of GDF-based measures of profit efficiency}

We use model (3) to highlight some general properties of the GDF technical efficiency measure. We follow the Färe and Lovell (1978) axioms of indication, monotonicity and homogeneity to explore the properties of the GDF technical efficiency measure.

\section{Intuitive homogeneity}

The GDF technical efficiency measure in (3) is subhomogeneous of degree -2 (ie, when inputs are halved and outputs are doubled, the measure of efficiency increases 
by a factor of at least four times) (see Appendix for proof). To the authors' knowledge there is no non-oriented efficiency measure in the literature that satisfies homogeneity of degree -2 . When we look just at one side (inputs or outputs) it seems intuitive to say that if all outputs double, the measure of efficiency should double (homogeneity of degree -1). When both inputs and outputs are being changed, homogeneity of degree -1 is not intuitive as a simultaneous change in both inputs and outputs should bring about a larger change in efficiency than when only inputs or outputs are changed. Nevertheless, most of the existing non-oriented measures in the literature satisfy degree of (sub)homogeneity -1 , like for example the hyperbolic measure or the Russell graph measure of technical efficiency (Färe et al, 1985).

\section{Monotonicity}

The GDF technical efficiency measure in (3) is weakly monotonous on inputs and on outputs. That is, when inputs increase keeping outputs constant and/or outputs decrease keeping inputs constant the measure cannot improve (see Appendix for proof).

\section{Indication}

The GDF incorporates all the sources of inefficiency, since the equality constraints in model (3) result, by definition, in zero slacks. This means that the GDF-based measure of technical efficiency is $1(100 \%)$ if and only if the unit being assessed is Pareto-efficient.

\section{Lower and upper bounds}

The GDF technical efficiency in (3) varies between 0 and 1 (see Appendix for proof).

\section{Measuring profit efficiency}

Within the DEA framework, the starting point of a profit analysis is the calculation of maximum attainable profit. This can be done using the model shown in (4) (eg Färe et al, 1994, p 213).

$$
\begin{aligned}
\max _{\lambda_{j}, y_{r}, x_{i}} & \left\{\sum_{r=1}^{s} p_{r o} y_{r}-\sum_{i=1}^{m} w_{i o} x_{i} \mid \sum_{j=1}^{n} \lambda_{j} y_{r j}-y_{r} \geqslant 0, r=1, \ldots, s ;\right. \\
& \sum_{j=1}^{n} \lambda_{j} x_{i j}-x_{i} \leqslant 0, i=1, \ldots, m \\
& \left.\sum_{j=1}^{n} \lambda_{j}=1, \lambda_{j} \geqslant 0, j=1, \ldots, n\right\}
\end{aligned}
$$

where $p_{\text {ro }}$ and $w_{i o}$ are, respectively, the price of output $r$ and input $i$ unit $o$ faces, and the rest of the notation is as previously defined. Model (4) assures profit maximization in the long run as no factors are considered fixed. Furthermore, it considers no other constraints apart from technological (though see Färe et al (1990), where expenditure constraints were added to (4)). Model (4) assumes VRS since for a technology exhibiting globally constant returns to scale (CRS) either the maximum profit level is zero or the solution of the maximum profit model is undefined (eg Varian, 1992; Färe et al, 1994). The implications of assuming VRS in (4) are: (i) We do not assume perfectly competitive markets since under this assumption all firms have zero profits in the long run, whereas in (4) maximum profit may be positive. (ii) Scale efficiency cannot be calculated as a component of overall profit efficiency. In order to make this possible the maximum profit model (4) should be applied under CRS (eg Färe et al, 1994). (iii) Maximum profit units do not need to be most productive scale size (mpss) units in the sense of Banker (1984). That is, maximum profit units do not need to be scale efficient (see also Kuosmanen, 1999). The implications resulting from a VRS assumption will be further addressed later in the paper.

\section{Brief review of existing approaches}

In this section, we briefly review existing approaches to measure and decompose profit efficiency by means of the technically and profit-inefficient unit $A$ in Figure 1.

Unit $A$ achieves maximum profit when it is projected on the profit frontier (say at $A^{*}$ ), where maximum profit equals that of unit B, a maximum profit unit. If overall profit efficiency were to be measured by means of a ratio between profit at two points, then the overall profit efficiency of unit $A$ would be given by the ratio $\Pi / \Pi^{*}$ (see eg Banker and Maindiratta, 1988; Cooper et al, 2000, who used this ratiobased approach within the DEA framework). The technical profit efficiency of this unit can also be calculated by a ratio of profits, namely as $\Pi / \Pi^{\prime}$, where $\Pi^{\prime}$ is the profit at the technically efficient projection $A^{\prime}$ of $A$. The allocative profit efficiency of $A\left(\Pi^{\prime} / \Pi^{*}\right)$ can now be calculated by decomposition from $\left(\Pi / \Pi^{*}\right)=\left(\Pi / \Pi^{\prime}\right) \times\left(\Pi^{\prime} / \Pi^{*}\right)$. This ratio-based approach is analogous to what is usually done in cost or

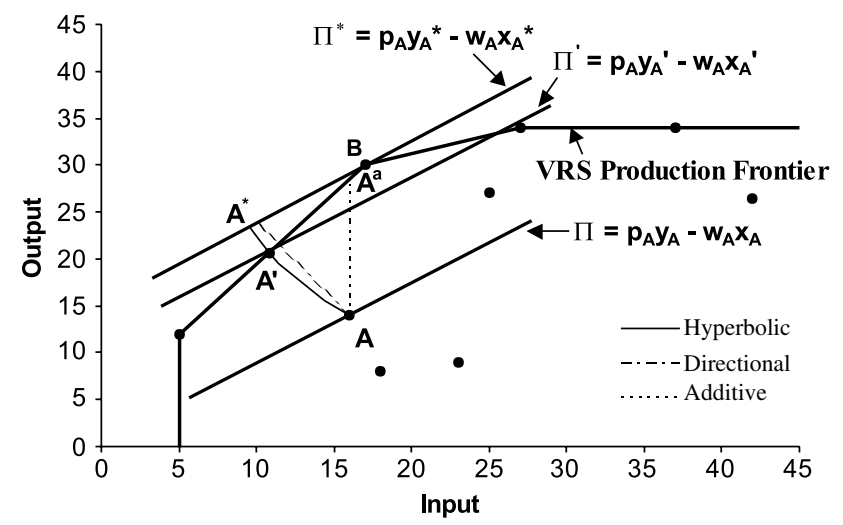

Figure 1 Profit efficiency measurement. 
revenue settings, where ratios of cost or revenue represent efficiency. In such settings, however, there is no possibility of negative costs or revenues. This is not the case with profits that can be negative resulting in negative profit efficiency measures that are hard to interpret. The problem of negative profits was not recognized as such by some authors. For example, Berger and Mester (2000, p 98) state that 'profit efficiency can be negative, since firms can throw away more than $100 \%$ of their potential profits'. Others like Banker and Maindiratta (1988) assumed that all production units exhibited positive profit. Finally some authors have acknowledged this problem and solved it either by using revenue/cost ratios, which can never be negative (see eg Cooper et al, 2000; Kuosmanen, 1999) or by using differences between profits, rather than ratios, to avoid negative efficiency measures (eg Berger et al, 1993; Coelli et al, 2002). (Note that under the revenue/cost ratio approach the profit efficiency of unit $A$ (see Figure 1) would be defined as a ratio of revenue-to-cost so that: $\left(\mathrm{p}_{\mathrm{A}} \mathrm{y}_{\mathrm{A}} /\right.$ $\left.\mathrm{w}_{\mathrm{A}} \mathrm{x}_{\mathrm{A}}\right) /\left(\mathrm{p}_{\mathrm{A}} \mathrm{y}_{\mathrm{A}}^{*} / \mathrm{w}_{\mathrm{A}} \mathrm{x}_{\mathrm{A}}^{* *}\right)$ where the double star is the optimal solution of: $\max \left\{\mathrm{p}_{\mathrm{A}} \mathrm{y} / \mathrm{w}_{\mathrm{A}} \mathrm{x} \mid(\mathbf{x}, \mathbf{y}) \in T\right\}$ (see for details Cooper et al, 2000).)

Rather than using the above ratio-based approach some authors defined overall profit efficiency as being a measure reflecting the required adjustments on the input/output levels of unit $A$ that moves it to point $A^{*}$ on the profit frontier. For example, the hyperbolic model of Färe et al (1985) defines the technical efficiency of unit $A$ as being $\theta_{\mathrm{A}}$ defined in $\left\{\theta_{A} \mid\left(\mathbf{x}_{\mathbf{A}} \theta_{A}, \mathbf{y}_{\mathbf{A}} / \theta_{A}\right) \in T\right\}$. In accordance with this hyperbolic path, the overall profit efficiency $\left(\phi_{A}^{h}\right)$ of unit $A$, is derived by solving $\Pi^{*}=\mathbf{P}_{\mathrm{A}}\left(\mathbf{y}_{\mathrm{A}} / \phi_{A}^{h}\right)-\mathbf{w}_{\mathbf{A}} \mathbf{x}_{\mathbf{A}} \phi_{A}^{h}$, where [ $\left.\Pi^{*}\right]$ is the maximum profit of $A$ calculated through model (4). That is, overall profit efficiency $\left(\phi_{A}^{h}\right)$ represents the amount by which inputs and outputs should be hyperbolically adjusted, so that they are projected on the profit boundary. The overall profit efficiency can then be decomposed as: $\phi_{A}^{h}=\theta_{A} \times \gamma_{A}^{h}$, where $\gamma_{A}^{h}$ is the allocative efficiency.

The directional model of Chambers et al $(1996,1998)$ follows a procedure that is similar to that of the hyperbolic model, except that the overall profit efficiency $\left(\phi_{A}^{d}\right)$, would decompose as: $\phi_{A}^{d}=\beta_{\mathrm{A}}+\gamma_{A}^{d}$, where $\beta_{A}$ represents technical inefficiency, calculated through the directional model, and $\gamma_{A}^{d}$ represents allocative inefficiency (for details see Chambers et al, 1998).

When the additive model of Charnes et al (1985) is used, then a technically efficient target $\left(A^{a}\right.$ in Figure 1 , whose profit is $\Pi^{a}$ ), and a maximum profit target ( $B$ in Figure 1, whose profit is II*) are identified. Using these targets Cooper et al $(1999,2000)$ decomposed the profit lost due to overall profit inefficiency into the profit lost due to technical and allocative inefficiency (ie $\left(\Pi^{*}-\Pi\right)=\left(\Pi^{a}-\Pi\right)+\left(\Pi^{*}-\Pi^{a}\right)$ ). This relationship is not, however, expressed in efficiency terms but in absolute profit values (see Berger et al, 1993; Coelli et al, 2002, who also used profit differences, though not using the additive model).
The foregoing approaches have certain disadvantages in a practical context which the profit efficiency measure we put forward in this paper overcomes. The key drawbacks of the foregoing measures are as follows.

\section{Negative efficiency measures}

It is possible for the ratio-based profit efficiency approaches to result in a negative measure of efficiency when the profit is negative (a loss). Such measures generally cannot be interpreted in a practical way to reflect distance from maximum profit and are therefore problematic. Efficiency measures which take only positive values are to be preferred. The measure of efficiency we put forward here can only take positive values.

\section{Reference to infeasible points}

The hyperbolic and directional models may calculate overall profit efficiency with reference to infeasible points such as $A^{*}$ in Figure 1. This can also happen in 'oriented' cost or revenue settings, but in these cases projections on infeasible points can be interpreted in terms of ratios of inputs (outputs) between the observed and the infeasible point because such ratios match the ratio of minimum cost (maximum revenue) to that at the observed point. That is, there is a dual cost or revenue interpretation of efficiency measures. This is no longer so in the non-oriented profit setting. For example, if we assume a hyperbolic path is followed from $A$ to $A^{*}$ in Figure 1, then the required adjustments in inputs and outputs are given by $\phi_{A}$, as $x_{A^{*}} / x_{A}=y_{A} / y_{A^{*}}=\phi_{A}$. The profit ratio, on the other hand equals $\left(\Pi / \Pi^{*}\right)=\left(p_{A} y_{A}-w_{A} x_{A}\right) /\left(p_{A} y_{A^{*}}-w_{A} x_{A^{*}}\right)$ $=\left(p_{A} y_{A}-w_{A} x_{A}\right) /\left(p_{A} y_{A} / \phi_{A}-w_{A} x_{A} \phi_{A}\right)$, which differs from $\phi_{A}$ (Note that this statement is valid for all paths).

\section{Accounting for slacks}

The calculation of technical (in)efficiency through the hyperbolic or directional models assumes the same factor $(\theta$ or $\beta)$ associated simultaneously with inputs and outputs. The resulting efficiency measures do not account, therefore, for all the sources of inefficiency, namely those associated with slacks. This is an important problem in a context where overall efficiency is being measured because what is not captured by technical efficiency will be incorporated into allocative efficiency, which may therefore be incorrectly estimated. The measure of efficiency we put forward in this paper accounts for all sources of inefficiency.

\section{The GDF for measuring and decomposing profit efficiency}

Consider an observed point (x, y), a maximum profit point $\left(\mathbf{x}^{*}, \mathbf{y}^{*}\right)$, and a technically efficient point $\left(\mathbf{x}^{\prime}, \mathbf{y}^{\prime}\right)$, then a profit 
efficiency measure of unit $o$ calculated through the GDF can be decomposed as shown in (5).

$$
\begin{aligned}
\text { Overall profit efficiency } & =\frac{\left(\prod_{i} \frac{x_{i o}^{*}}{x_{i o}}\right)^{1 / m}}{\left(\prod_{r} \frac{y_{r o}^{*}}{y_{r o}}\right)^{1 / s}} \\
& =\frac{\left(\prod_{i} \frac{x_{i o}^{\prime}}{x_{i o}}\right)^{1 / m}}{\left(\prod_{r} \frac{y_{r o}^{\prime}}{y_{r o}}\right)^{1 / s}} \times \frac{\left(\prod_{i} \frac{x_{i o}^{*}}{x_{i o}^{*}}\right)^{1 / m}}{\left(\prod_{r} \frac{y_{r o}^{*}}{y_{r o}^{\prime}}\right)^{1 / s}}
\end{aligned}
$$

That is, Overall profit eff. $=$ Technical profit eff. $\times$ Allocative profit eff. Note that this decomposition is valid whatever the method used to calculate technical efficiency, and whatever the maximum profit point is. This is an advantage of the GDF measure of efficiency over other existing nonoriented measures such as the Russell additive measure of Färe et al (1985), the SBM (slacks-based measure) of Tone (2001) or the RAM model of Cooper et al (1999), which cannot be decomposed in the way shown above.

For calculating overall profit efficiency we shall first use model (4) and then apply the geometric distance function in (2) to measure the 'distance' between observed points and maximum profit points as given by (4). The resulting GDF measure is the overall profit efficiency.

The GDF overall profit efficiency can take any positive value. The measure takes the value 1 when the two points (eg maximum profit point and observed point) used are coincident. However, the converse is not true and the GDF overall profit efficiency can be 1 even when the two points used in the measure are not coincident. For example, if one input is halved and another is doubled the result in the numerator of the GDF is 1 , which does not mean that inputs did not change but that on average they stayed the same. Because of the averaging process within the computation of the overall profit efficiency it is necessary to further decompose it, so that one can understand and interpret its value. In the next section, we will show how each component of (5) is calculated and interpreted. We also show an alternative measure of overall efficiency, satisfying duality properties with the GDF technical efficiency measure that does not suffer from this problem.

\section{Decomposing the GDF overall profit efficiency}

Recall that overall profit efficiency can be decomposed as technical profit efficiency $\times$ allocative profit efficiency. The calculation of technical profit efficiency is done in this paper using the geometric distance function in (3). Note, however, that any non-oriented model could be used to identify technical efficient targets and the GDF could be used $a$ posteriori to calculate the distance between observed points and technical efficient targets (see for example Portela and
Thanassoulis (2005), where a closest target procedure was used to calculate technical efficient points).

Given the above, we define technical profit efficiency as the distance between the observed point and the technical efficient point identified through model (3). In moving from the observed to the technical efficient point a unit may change the mix of inputs and/or outputs but these changes in mix are to attain technical efficiency and not to respond to factor prices, and so they do not relate to attaining allocative efficiency.

In terms of interpretation, as the technical profit efficiency component ranges from 0 to 1 (see the Appendix), a value of 1 means the observed point is Pareto-efficient, while a value below 1 means the observed point is not Pareto-efficient.

Note that the way technical efficiency is measured has obvious implications for the components of overall inefficiency that are attributed to technical and allocative inefficiency, respectively. If we had chosen closest targets as in Portela and Thanassoulis (2005) we would have been 'minimizing' the component attributable to technical inefficiency and 'maximizing' the component that is attributable to allocative inefficiency. By choosing the targets given by model (3) the component attributable to technical inefficiency will be higher.

Having calculated the overall profit efficiency and the technical profit efficiency, the allocative profit efficiency can be calculated as the ratio of overall profit efficiency and technical profit efficiency (see decomposition in (5)). The allocative profit efficiency reflects movements from a technically efficient point $\left(\mathbf{x}^{\prime}, \mathbf{y}^{\prime}\right)$ to a maximum profit point $\left(\mathbf{x}^{*}, \mathbf{y}^{*}\right)$. Such movements imply changes in the mix of inputs and/or outputs that are dictated by factors prices. However, movements from a technical efficient point to a maximum profit point (both on the frontier of $T$ ) may not only imply changes in mix but also changes in scale size. As noted by Lovell and Sickles (1983, p 54) for a profit setting, 'in the single output single input case all allocative inefficiency is scale inefficiency'.

Depending on the combination of these effects allocative profit efficiency, can be higher or lower than 1. In Portela and Thanassoulis (2005), the authors propose a procedure to disentangle scale and mix effects from the allocative efficiency measure. We do not, however, present this decomposition in this paper for the sake of brevity.

\section{Illustration of the GDF profit efficiency measure and its decomposition}

To illustrate the calculation of overall profit efficiency and its decomposition, we will use the data shown in Table 1. These are the data used in Ali and Seiford (1993), except for the hypothetical input/output prices, which we have added.

We used model (4) to find maximum profit targets, and the GDF profit efficiency measure defined in (2) to calculate 
Table 1 Illustrative data for units producing one output using two inputs

\begin{tabular}{llrllllllllrr}
\hline & Unit & 1 & 2 & 3 & 4 & 5 & 6 & 7 & 8 & 9 & 10 \\
\hline Output & $y$ & 12 & 14 & 25 & 26 & 8 & 9 & 27 & 30 & 31 & 26.5 & 12 \\
Input 1 & $x_{1}$ & 5 & 16 & 16 & 17 & 18 & 23 & 25 & 27 & 37 & 42 \\
Input 2 & $x_{2}$ & 13 & 12 & 26 & 15 & 14 & 6 & 10 & 22 & 14 & 25 \\
Price of $y$ & $p$ & 20 & 22 & 24 & 25 & 23 & 19 & 18 & 21 & 23 & 22 & 25 \\
Price of $x_{1}$ & $w_{1}$ & 6 & 7 & 5 & 4 & 5.5 & 6.5 & 7.5 & 8 & 4 & 5.5 & 6 \\
Price of $x_{2}$ & $w_{2}$ & 9 & 8 & 7.5 & 6 & 8 & 5 & 9 & 10 & 10.5 & 9.5 \\
\hline
\end{tabular}

Table 2 Overall profit efficiency measurement

\begin{tabular}{|c|c|c|c|c|c|c|}
\hline Unit & Actual profit & Maximum profit & Peer unit & Input change & Output change & GDF profit efficiency (\%) \\
\hline 1 & 93 & 300 & 7 & 1.96 & 2.25 & 87.16 \\
\hline 2 & 100 & 339 & 7 & 1.14 & 1.93 & 59.17 \\
\hline 3 & 325 & 454 & 9 & 1.12 & 1.24 & 89.99 \\
\hline 4 & 492 & 543 & 9 & 1.43 & 1.19 & 119.54 \\
\hline 5 & -27 & 403.5 & 7 & 0.99 & 3.38 & 29.51 \\
\hline 6 & -8.5 & 308.5 & 4 & 1.36 & 2.89 & 47.05 \\
\hline 7 & 208.5 & 208.5 & 7 & 1.00 & 1.00 & 100 \\
\hline 8 & 194 & 267 & 7 & 0.65 & 0.90 & 72.08 \\
\hline 9 & 418 & 418 & 9 & 1.00 & 1.00 & 100 \\
\hline 10 & 114.5 & 361.5 & 7 & 0.49 & 1.02 & 47.89 \\
\hline 11 & 125.5 & 440 & 7 & 1.72 & 2.25 & 76.22 \\
\hline
\end{tabular}

the distance between observed points and maximum profit targets. The results are presented in Table 2, where we also show results for the numerator and denominator of the GDF measure, called input change and output change, respectively.

There are two units that are overall profit efficient (units 7 and 9). All the other units are overall profit inefficient since they fail to maximise profits given their input and output prices. (We comment on the 'odd' efficiency result of unit 4 later.)

Most units in Table 2 achieve profit efficiency by increasing simultaneously inputs and outputs, the latter increment being on average more than proportional to the former (Unit 8 is an exception, as it shows no increase but decrease in both inputs and outputs). Note that unit 4 is the only one that should on average increase outputs less than proportionally to inputs. Such a result is related with the type of returns to scale that apply at this unit position as will become clear later.

\section{Decomposition of overall profit efficiency}

Technical efficiency results, from model (3), are shown in Table 3, where only technically inefficient units are presented.

Allocative profit efficiency results for our illustrative example are shown in Table 4, where we summarize all results attained and also show the type of RTS that apply at each technically efficient point (RTS were identified through the procedure of Färe et al, 1985).
Knowing the RTS characteristics of each unit we can now easily understand why unit 4 has an overall and allocative profit efficiency greater than $100 \%$. Unit 4 lies on a region of CRS and must move, in order to be profit efficient, to unit 9, a DRS unit. As it is well known CRS points are most productive scale size (mpss) in the sense of Banker (1984). This means that by comparing a mpss unit such as 4 with a non-mpss unit such as 9 the productivity will decrease. For the specific case of unit 4 we have partial productivity ratios at its original position of: $y / x_{1}=26 / 17$ and $y / x_{2}=26 / 15$, and at the maximum profit point (unit 9) partial productivity ratios are: $y / x_{1}=31 / 37$ and $y / x_{2}=31 / 14$. The aggregation of these productivity ratios through a geometric mean results in an aggregate productivity of $1.628183(\sqrt{26 / 17 \times 26 / 15})$ at the original position of unit 4 , and of 1.362062 $(\sqrt{31 / 37 \times 31 / 14})$ at its maximum profit position. The ratio between these two values (1.628183/1.362062) gives $119.54 \%$, indicating that the aggregate productivity of unit 4 is higher than the aggregate productivity at its maximum profit target point. Note that an allocative profit efficiency measure greater than 1 will always indicate a productivity change that is not beneficial in scale terms for the unit being assessed, although it is so in profit terms, because of the relative input/output prices.

\section{Profitability efficiency — an alternative to profit efficiency}

Profit is defined as revenue minus cost but an alternative measure of a firm's overall performance is profitability, 
Table 3 Technical efficiency measurement results

\begin{tabular}{lllll}
\hline Unit & 2 & 5 & 10 & 11 \\
\hline Observed $\left(y, x_{1}, x_{2}\right)$ & $(14,16,12)$ & $(8,18,14)$ & $(26.5,42,25)$ & $(12,5,17)$ \\
Model $(3)$ targets & $(21.11,16,12)$ & $(25.63,18,14)$ & $(27,25,10)$ & $(12,5,13)$ \\
GDF & $66.34 \%$ & $31.21 \%$ & $47.89 \%$ & $87.45 \%$ \\
Peer units & $\lambda_{1}=0.38, \lambda_{4}=0.17, \lambda_{7}=0.45$ & $\lambda_{1}=0.04, \lambda_{4}=0.78, \lambda_{7}=0.18$ & $\lambda_{7}=1$ & $\lambda_{1}=1$ \\
\hline
\end{tabular}

Table 4 General efficiency measurement results

\begin{tabular}{lcccl}
\hline Unit & $\begin{array}{c}\text { Overall profit } \\
\text { GDF }(\%)\end{array}$ & $\begin{array}{c}\text { Technical } \\
\text { GDF }(\%)\end{array}$ & $\begin{array}{c}\text { Allocative } \\
\text { GDF }(\%)\end{array}$ & RTS \\
\hline 1 & 87.16 & 100.00 & 87.16 & CRS \\
2 & 59.17 & 66.33 & 89.20 & IRS \\
3 & 89.99 & 100.00 & 89.99 & DRS \\
4 & 119.54 & 100.00 & 119.54 & CRS \\
5 & 29.51 & 31.21 & 94.55 & IRS \\
6 & 47.05 & 100.00 & 47.05 & IRS \\
7 & 100.00 & 100.00 & 100.00 & CRS \\
8 & 72.08 & 100.00 & 72.08 & DRS \\
9 & 100.00 & 100.00 & 100.00 & DRS \\
10 & 47.89 & 47.89 & 100.00 & DRS \\
11 & 76.22 & 87.50 & 87.16 & CRS \\
\hline
\end{tabular}

defined as revenue divided by cost (see Balk, 2001, p 6). One would be interested in the profitability ratio to take scale out of measuring profit and simply reflect the 'mark up' on input costs that is being secured by a unit. Profitability complements the more traditional measures of accounting profit in absolute rather than relative terms. Traditionally, the profitability measure for unit $o$ is defined as $\sum_{r} p_{r o} y_{r o}$ $\sum_{i} w_{i o} x_{i o}$ (see eg Kuosmanen, 1999; Cooper et al, 2000), but we can use the GDF to calculate a profitability ratio of unit $o$, which is given by (6).

$$
\frac{\left(\prod_{r} p_{r o} y_{r o}\right)^{1 / s}}{\left(\prod_{i} w_{i o} x_{i o}\right)^{1 / m}}
$$

Thus, the measure of profitability defined above uses output revenues and input costs aggregated, respectively, through a geometric mean. The maximum profitability that a unit $o$ could attain is yielded by the optimal value of the objective function in (4).

$$
\begin{gathered}
\max _{\lambda_{j}, y_{r}, x_{i}}\left\{\frac{\left(\prod_{r} p_{r o} y_{r}\right)^{1 / s}}{\left(\prod_{i} w_{i o} x_{i}\right)^{1 / m}} \mid \sum_{j=1}^{n} \lambda_{j} y_{r j}-y_{r} \geqslant 0, \quad r=1, \ldots, s,\right. \\
\sum_{j=1}^{n} \lambda_{j} x_{i j}-x_{i} \leqslant 0, \quad i=1, \ldots, m, \\
\left.\lambda_{j} \geqslant 0, j=1, \ldots, n\right\}
\end{gathered}
$$

Notation in (7) is as previously defined. In model (7) the convexity constraint is omitted since the maximum profitability 'unit' (observed or reflected) will always be a CRS efficient unit and therefore model (7) will always have at least one optimal solution in which the sum of the intensity variables $\lambda$ s will be 1 (see Appendix for proof). One implication of this is that model (7) identifies input-output levels that render unit $o$ scale efficient with maximum profitability. This is in contrast to model (4), which did not necessarily yield scale-efficient input-output target levels for the unit being assessed. (This was why as we saw some units such as 4 in the above example could have overall profit efficiency higher than $100 \%$.)

One very interesting property of the profitability efficiency measure defined above is that it is given by the ratio of observed profitability to maximum profitability, mirroring the usual definition of radial economic efficiency in DEA (eg cost efficiency is the ratio of minimum cost to observed cost). To see this let us denote maximum profitability as $\Gamma^{*}$ and observed profitability as $\Gamma^{o}$ then

$$
\Gamma^{*} \geqslant \frac{\left(\prod_{r} p_{r o}\left(y_{r o} \beta_{r o}^{\prime}\right)\right]^{1 / s}}{\left(\prod_{i} w_{i o}\left(x_{i o} \theta_{i o}^{\prime}\right)\right]^{1 / m}}
$$

where the input and output levels in the RHS of (8) represent a technically efficient reflection of vector $\left(\mathbf{x}_{\mathbf{o}}, \mathbf{y}_{\mathbf{o}}\right)$ on a CRS technology using the factors $\theta_{i o}^{\prime}$ and $\beta_{\text {ro }}^{\prime}$ that can be determined through the model in (3) when the convexity constraint is dropped. This means that

$$
\Gamma^{*} \geqslant \frac{\left(\prod_{r} p_{r o} y_{r o}\right)^{1 / s} \times\left(\prod_{r} \beta_{r o}^{\prime}\right)^{1 / s}}{\left(\prod_{i o} w_{i o} x_{i o}\right)^{1 / m} \times\left(\prod_{i} \theta_{i o}^{\prime}\right)^{1 / m}}
$$

or

$$
\Gamma^{*} \geqslant \Gamma^{o} \times \frac{1}{G D F_{c}} \Leftrightarrow \frac{\Gamma^{o}}{\Gamma^{*}} \leqslant G D F_{c}
$$

meaning that

$$
\frac{\Gamma^{o}}{\Gamma^{*}}=G D F_{c} \times \mathrm{AE}
$$

where $G D F_{c}$ is the GDF technical efficiency of $\left(\mathbf{x}_{\mathbf{o}}, \mathbf{y}_{\mathbf{o}}\right)$ when a CRS technology is used. Clearly AE will then be a measure of the allocative efficiency of $\left(\mathbf{x}_{\mathbf{o}}, \mathbf{y}_{\mathbf{o}}\right)$. Note that AE lies between 0 and 1, unlike the case where allocative efficiency is measured with reference to profit rather than profitability efficiency. Profitability efficiency can never be above 1 since observed profitability is never higher than maximum profitability. This did not happen for profit efficiency that could be above 1 as explained in the previous sections. 
The expression in (11) is equivalent to

$$
\begin{gathered}
\text { Overall profitability efficiency }=\frac{\left(\prod_{i} \frac{x_{i o}^{*}}{x_{i o}}\right)^{1 / m}}{\left(\prod_{r} \frac{y_{r o}^{*}}{y_{r o}}\right)^{1 / s}} \\
=\frac{\left(\prod_{i} \frac{x_{i o}^{\prime}}{x_{i o}}\right)^{1 / m}}{\left(\prod_{r} \frac{y_{r o}^{\prime}}{y_{r o}}\right)^{1 / s}} \times \frac{\left(\prod_{i} \frac{x_{i o}^{*}}{x_{i o}^{\prime}}\right)^{1 / m}}{\left(\prod_{r} \frac{y_{r o}^{*}}{y_{r o}^{\prime}}\right)^{1 / s}}
\end{gathered}
$$

which is in fact the first decomposition we put forward in (5), the differences being that $\left(\mathbf{x}^{*}, \mathbf{y}^{*}\right)$ is the optimal vector resulting from model (7) and not from model (4), and the technical efficient target $\left(\mathbf{x}^{\prime}, \mathbf{y}^{\prime}\right)$ is calculated in relation to a CRS technology rather than in relation to a VRS technology as in (3). If we introduce in (12) factor prices we can simplify the expression as

$$
\frac{\Gamma^{o}}{\Gamma^{*}}=\frac{\Gamma^{o}}{\Gamma^{\prime}} \times \frac{\Gamma^{\prime}}{\Gamma^{*}}
$$

where $\Gamma^{\prime}$ is profitability at the technical efficient point $\left(\mathbf{x}^{\prime}, \mathbf{y}^{\prime}\right)$. This means that both the GDF technical efficiency and allocative efficiency measures have a dual profitability interpretation. For example, a GDF technical efficiency of $50 \%$ means that observed profitability is $50 \%$ of profitability at the technically efficient target, and therefore the unit can improve its profitability by moving to this target.

The above decomposition in (11) can be extended to retrieve the scale efficiency component of unit $o$. Thus if we calculate the GDF technical efficiency both in relation to a CRS frontier $\left(G D F_{c}\right.$, calculated using (3) without the convexity constraint) and in relation to the VRS frontier $\left(G D F_{v}\right.$, calculated using (3)), we can expand the decomposition in (11) to

$$
\frac{\Gamma^{o}}{\Gamma^{*}}=G D F_{v} \times \mathrm{AE} \times S E
$$

where SE stands for scale efficiency and equals $G D F_{c} / G D F_{v}$. This scale efficiency component is interpreted in the usual way, reflecting the distance between the VRS and the CRS frontiers.

\section{Application of the profitability efficiency model to our illustrative example}

Applying the profitability efficiency model to our illustrative example gives the results in Table 5 .

In the illustrative example, a single unit is identified as the profitability maximizing unit-unit 7, whose profitability efficiency is $100 \%$. All remaining units have profitability efficiency lower than $100 \%$. Profitability efficiency is equal to profit efficiency for those units whose maximum profit peer unit was unit 7. This was not the case for units 3, 4, 6, and 9 , which therefore have a profitability efficiency that is different from profit efficiency. This means that maximizing profitability for these units is not equivalent to maximizing accounting profits. Units with $100 \%$ profitability efficiency generally, but not always, have scope to increase accounting profits further. Profits may also reduce in movements from the observed to the maximum profitability point. This happens for unit 9 whose observed profit is 418 , and profit at the maximum profitability point is 416 . This means that if this unit adjusted to the proper scale size this would mean a loss in accounting profit. (The cause of this is further discussed below.)

The technical efficiency of the units is exactly the same as before, and therefore profitability efficiency decomposes now as shown in Table 6.

From Table 6 it is clear that the main source of profitability inefficiency is scale inefficiency, since allocative efficiency values are in general high. As we saw before, for all units except unit 9, movements towards the maximum profitability point imply an increase in accounting profit. The fact that this does not happen for unit 9 is due to its scale inefficiency. On the other hand, the profitability inefficiency of units 1 and 4 is completely attributable to allocative inefficiency. That is, these units employ a wrong mix of inputs and outputs given the prices they face, and therefore a change in this mix would improve their profitability. In contrast, the profitability inefficiency of unit 10 is completely attributable to its technical inefficiency. For the

\begin{tabular}{|c|c|c|c|c|c|c|}
\hline Unit & Actual profit & Actual profitability & Maximum profitability & Profitability efficiency (\%) & Peer & Profit at peer \\
\hline 1 & 93 & 4.051 & 4.648 & 87.16 & 7 & 300 \\
\hline 2 & 100 & 2.970 & 5.020 & 59.17 & 7 & 339 \\
\hline 3 & 325 & 4.804 & 6.693 & 71.78 & 7 & 448 \\
\hline 4 & 492 & 8.309 & 8.714 & 95.35 & 7 & 515 \\
\hline 5 & -27 & 1.747 & 5.921 & 29.51 & 7 & 403.5 \\
\hline 6 & -8.5 & 2.553 & 5.691 & 44.87 & 7 & 300.5 \\
\hline 7 & 208.5 & 3.741 & 3.741 & 100.00 & 7 & 208.5 \\
\hline 8 & 194 & 2.890 & 4.009 & 72.09 & 7 & 267 \\
\hline 9 & 418 & 4.834 & 6.060 & 79.76 & 7 & 416 \\
\hline 10 & 114.5 & 2.489 & 5.197 & 47.89 & 7 & 361.5 \\
\hline 11 & 125.5 & 4.556 & 5.978 & 76.22 & 7 & 440 \\
\hline
\end{tabular}
remaining units, profitability inefficiency is attributable to a mix of technical, allocative and scale inefficiency.

Table 5 Overall profitability efficiency measurement 
Table 6 Profitability efficiency decomposition

\begin{tabular}{|c|c|c|c|c|c|}
\hline Unit & Profitability efficiency (\%) & Technical GDF efficiency (\%) & Allocative efficiency (\%) & Scale efficiency (\%) & $R T S$ \\
\hline 1 & 87.16 & 100.00 & 87.16 & 100.00 & CRS \\
\hline 2 & 59.17 & 66.33 & 100.00 & 89.20 & IRS \\
\hline 3 & 71.78 & 100.00 & 94.00 & 76.37 & DRS \\
\hline 4 & 95.35 & 100.00 & 95.35 & 100.00 & CRS \\
\hline 5 & 29.51 & 31.21 & 95.35 & 99.17 & IRS \\
\hline 6 & 44.87 & 100.00 & 95.35 & 47.05 & IRS \\
\hline 7 & 100.00 & 100.00 & 100.00 & 100.00 & CRS \\
\hline 8 & 72.08 & 100.00 & 95.35 & 75.60 & DRS \\
\hline 9 & 79.76 & 100.00 & 100.00 & 79.76 & DRS \\
\hline 10 & 47.89 & 47.89 & 100.00 & 100.00 & DRS \\
\hline 11 & 76.22 & 87.45 & 87.16 & 100.00 & CRS \\
\hline
\end{tabular}

\section{Conclusion}

This paper proposes a novel way of calculating profit efficiency through a geometric distance function (GDF). The advantage of the GDF efficiency measure is that it is easily decomposed, and therefore we can identify whether the sources of profit inefficiency are due to technical inefficiency or allocative inefficiency. However, when one uses the accounting concept of profit it may happen that profit efficiency is higher than $100 \%$ since maximum profit units do not need to be scale efficient. In addition, there is no dual profit interpretation of technical efficiency when the accounting concept of profit is used. For this reason, we introduce a measure of profitability efficiency, also based on the GDF, which has maximum value of $100 \%$, and allows for a dual profitability interpretation of the GDF measure of technical efficiency. In addition, the profitability efficiency measure makes it possible to retrieve scale efficiency enhancing thus the information obtained on the performance of a for-profit unit.

Acknowledgements - We acknowledge the financial support of the Portuguese Foundation for Science and Technology, and the European Social Fund. The contents of the paper are the responsibility of the authors.

\section{References}

Ali AI and Seiford LM (1993). The mathematical programming approach to efficiency analysis. In: Fried HO, Lovell CAK and Schmidt SS (eds). The Measurement of Productive Efficiency: Techniques and Applications. Oxford University Press, New York, Oxford, pp. 120-159.

Balk BM (2001). Scale efficiency and productivity change. J Prod Anal 15: 159-183.

Banker RD (1984). Estimating most productive scale size using data envelopment analysis. Euro J Opl Res 17: 35-44.

Banker RD and Maindiratta A (1988). Nonparametric analysis of technical and allocative efficiencies in poduction. Econometrica 56: $1315-1332$.

Berger AN, Hancock D and Humphrey DB (1993). Bank efficiency derived from the profit function. J Bank Fin 17: 314-347.
Berger AN and Mester LJ (2000). Inside the black box; what explains differences in the efficiencies of financial institutions? In: Harker PT and Zenios SA (eds). Performance of Financial Institutions: Efficiency, Innovation and Regulation. Cambridge University Press, Cambridge, UK, pp 93-150.

Chambers RG, Chung Y and Färe R (1996). Benefit and distance functions. $J$ Econ Theory 70: 407-419.

Chambers RG, Chung Y and Färe R (1998). Profit, directional distance functions, and Nerlovian efficiency. J Optim Theory and Appl 98: 351-364.

Charnes A, Cooper WW and Rhodes E (1978). Measuring efficiency of decision making units. Eur J Opl Res 2: 429-444.

Charnes A, Cooper WW, Golany B and Seiford L (1985). Foundations of data envelopment analysis for ParetoKoopmans efficient empirical production functions. $J$ Econom 30: $91-107$.

Coelli T, Grifell-Tatje and Perelman S (2002). Capacity utilisation and profitability: a decomposition of short run profit efficiency. Int J Product Econ 79: 261-278.

Cooper WW, Park KS and Pastor JT (1999). RAM: a range adjusted measure of inefficiency for use with additive models, and relations to other models and measures in DEA. $J$ Product Anal 11: 5-42.

Cooper WW, Seiford LM and Tone K (2000). Data Envelopment Analysis: A Comprehensive Text with Models, Applications, References and DEA-Solver Software. Kluwer Academic Publishers: Boston.

Färe R, Grosskopf S and Lee H (1990). A nonparametric approach to expenditure constrained profit maximization. Am J Agri Econ 12: $574-581$.

Färe R, Grosskopf S and Lovell AK (1994). Production Frontiers. Cambridge University Press: UK.

Färe R, Grosskopf S and Lovell CAK (1985). The Measurement of Efficiency of Production. Kluwer-Nijhoff Publishing: Boston.

Färe R, Grosskopf S and Zelenyuk V (2002). Finding common ground: efficiency indices Paper presented at the North American Productivity Workshop at Union College, Schenectady, NY.

Färe R and Lovell CAK (1978). Measuring the technical efficiency of production. $J$ Econo Theory 19: 150-162.

Kumbhakar SC (2001). Estimation of profit functions when profit is not maximum. Am J Agri Econ 83: 1-19.

Kuosmanen T (1999). Some remarks on scale efficiency and returns to scale in DEA. Helsinki School of Economics and Business Administration, Helsinki.

Lovell CAK and Sickles RC (1983). Testing efficiency hypothesis in joint production: a parametric approach. Rev Econ Stat 65: 51-58.

Pastor JT, Ruiz JL and Sirvent I (1999). An enhanced DEA Russell graph efficiency measure. Eur J Opl Res 115: 596-607. 
Portela MCAS and Thanassoulis E (2005). Profitability of a sample of Portuguese bank branches and its decomposition into technical and allocative components. Eur J Opl Res 162: 850-866.

Russell RR (1985). Measures of technical efficiency. J Econ Theory 35: $109-126$.

Tone K (2001). A slacks-based measure of efficiency in data envelopment analsysis. Eur J Opl Res 130: 498-509.

Varian HR (1992). Microeconomic Analysis, 3rd edn. W.W. Norton and Company: New York.

\section{Appendix}

Properties of the geometric distance function defined in model (3)

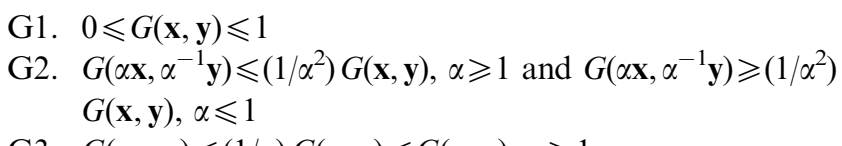

G3. $G(\alpha \mathbf{x}, \mathbf{y}) \leqslant(1 / \alpha) G(\mathbf{x}, \mathbf{y}) \leqslant G(\mathbf{x}, \mathbf{y}), \alpha \geqslant 1$

G4. $G(\mathbf{x}, \alpha \mathbf{y}) \leqslant \alpha G(\mathbf{x}, \mathbf{y}) \leqslant G(\mathbf{x}, \mathbf{y}), 0 \leqslant \alpha \leqslant 1$

G1 Proof The GDF cannot be greater than 1. In order for this to happen the numerator in (3) should be greater than the denominator. However, as every $\theta_{i}$ in the numerator is $\leqslant 1$, and every $\beta_{r}$ in the denominator is $\geqslant 1$, GDF $>1$ results in an impossibility. This means that the maximum value of $G(\mathbf{x}, \mathbf{y})$ is 1 , happening when the numerator equals the denominator. As every $\theta_{i}$ in the numerator is $\leqslant 1$, and every $\beta_{r}$ in the denominator is $\geqslant 1$, the equality between the numerator and denominator can only happen when all $\theta_{i}$ and all $\beta_{r}$ are 1 .

The GDF may be zero when some inputs (but not all, as we assume that it is not possible to produce outputs with zero inputs) are zero. For zero outputs the model cannot find a feasible solution as it would be possible to find an infinitely large $\beta_{\text {ro }}$ associated with the zero output.

G2 Proof This property states that $G(\mathbf{x}, \mathbf{y})$, satisfies subhomogeneity (eg Russell, 1985) of -2 degree. Indeed,

$$
\begin{aligned}
G\left(\alpha \mathbf{x}, \alpha^{-1} \mathbf{y}\right)= & \min \left\{\frac{\alpha\left(\prod_{i} \theta_{i}\right)^{1 / m}}{\alpha^{2} \alpha^{-1}\left(\prod_{r} \beta_{r}\right)^{1 / s}} \mid\left(\theta_{i}\left(\alpha x_{i o}\right), \beta_{r}\left(\alpha^{-1} y_{r o}\right)\right) \in T\right. \\
& \left.0 \leqslant \theta_{i} \leqslant 1, \beta_{r} \geqslant 1\right\} \Leftrightarrow \min \left\{\frac{\left(\prod_{i}\left(\alpha \theta_{i}\right)\right)^{1 / m}}{\alpha^{2}\left(\prod_{r}\left(\alpha^{-1} \beta_{r}\right)\right)^{1 / s}} \mid\right. \\
& \left.\left(\left(\theta_{i} \alpha\right) x_{i o},\left(\beta_{r} \alpha^{-1}\right) y_{r o}\right) \in T, 0 \leqslant \theta_{i} \leqslant 1, \beta_{r} \geqslant 1\right\} \\
& \Rightarrow G\left(\alpha \mathbf{x}, \alpha^{-1} \mathbf{y}\right) \leqslant \frac{1}{\alpha^{2}} G(\mathbf{x}, \mathbf{y}) \text { for } \alpha \geqslant 1, \\
& \text { and } G\left(\alpha \mathbf{x}, \alpha^{-1} \mathbf{y}\right) \geqslant \frac{1}{\alpha^{2}} G(\mathbf{x}, \mathbf{y}) \text { for } \alpha \leqslant 1
\end{aligned}
$$

G3 and G4 Proof These properties relate with the weak monotonicity properties of the geometric distance function. The input monotonicity implies that

$$
\begin{aligned}
G(\alpha \mathbf{x}, \mathbf{y})= & \min \left\{\frac{\alpha \frac{1}{\alpha}\left(\prod_{i} \theta_{i}\right)^{1 / m}}{\left(\prod_{r} \beta_{r}\right)^{1 / s}} \mid\left(\theta_{i}\left(\alpha x_{i o}\right), \beta_{r} y_{r o}\right) \in T\right. \\
& \left.0 \leqslant \theta_{i} \leqslant 1, \beta_{r} \geqslant 1\right\} \Leftrightarrow \min \left\{\frac{1}{\alpha} \frac{\left(\prod_{i}\left(\alpha \theta_{i}\right)\right)^{1 / m}}{\left(\prod_{r}\left(\beta_{r}\right)\right)^{1 / s}} \mid\right. \\
& \left.\left(\left(\theta_{i} \alpha\right) x_{i o}, \beta_{r} y_{r o}\right) \in T, 0 \leqslant \theta_{i} \leqslant 1, \beta_{r} \geqslant 1\right\} \\
& \Rightarrow G(\alpha \mathbf{x}, \mathbf{y}) \leqslant \frac{1}{\alpha} G(\mathbf{x}, \mathbf{y}) \text { for } \alpha \geqslant 1 \\
& \Rightarrow G(\alpha \mathbf{x}, \mathbf{y}) \leqslant(\mathbf{x}, \mathbf{y})
\end{aligned}
$$

The output monotonicity implies that

$$
\begin{aligned}
G(\mathbf{x}, \alpha \mathbf{y})= & \min \left\{\frac{\left(\prod_{i} \theta_{i}\right)^{1 / m}}{\alpha \frac{1}{\alpha}\left(\prod_{r} \beta_{r}\right)^{1 / s} \mid} \mid\left(\theta_{i} x_{i o}, \beta_{r}\left(\alpha y_{r o}\right)\right) \in T,\right. \\
& \left.0 \leqslant \theta_{i} \leqslant 1, \beta_{r} \geqslant 1\right\} \Leftrightarrow \min \left\{\alpha \frac{\left(\prod_{i}\left(\theta_{i}\right)\right)^{1 / m}}{\left(\prod_{r}\left(\alpha \beta_{r}\right)\right)^{1 / s}} \mid\right. \\
& \left.\left(\theta_{i} x_{i o}, \beta_{r}\left(\alpha y_{r o}\right)\right) \in T, 0 \leqslant \theta_{i} \leqslant 1, \beta_{r} \geqslant 1\right\} \\
& \Rightarrow G(\mathbf{x}, \alpha \mathbf{y}) \leqslant \alpha G(\mathbf{x}, \mathbf{y}) \text { for } \quad \alpha \leqslant 1, \\
& \Rightarrow G(\mathbf{x}, \alpha \mathbf{y}) \leqslant G(\mathbf{x}, \mathbf{y})
\end{aligned}
$$

\section{A unit of maximum profitability is always scale efficient}

Consider for the single input output case a unit $A\left(x_{A}, y_{A}\right)$ for which $y_{A} / x_{A}$ is maximum (being therefore a CRS efficient unit). If this unit is assessed at prices $\left(p_{A}, w_{A}\right)$ then clearly for this unit's prices $p_{A} y_{A} / w_{A} x_{A}>p_{A} y_{j} / w_{A} x_{j}$, for every $j \neq A$. Assessing unit $\mathrm{B}\left(x_{B}, y_{B}\right)$, for which $y_{B} / x_{B}$ is not maximum, at prices $\left(p_{B}, w_{B}\right)$ we cannot find for this unit's prices $p_{B} y_{B} /$ $w_{B} x_{B}>p_{B} y_{A} / w_{B} x_{A}$, since $y_{A} / x_{A}$ is maximum. Therefore, the above model (7) renders maximum profitability units that are also scale efficient. This reasoning can be extended to the multiple input/output case since the way we aggregate output revenues and input costs is through the geometric mean. Therefore replacing above $p_{j} y_{j} / w_{j} x_{j}$ by $\left(\Pi_{r} p_{r j} y_{r j}\right)^{1 / s} /$ $\left(\Pi_{i} w_{i j} x_{i j}\right)^{1 / m}$ maintains the reasoning valid. 